\title{
Recria de bezerras de corte em alternativas de uso da pastagem de azevém
}

\section{Dalton Roso ${ }^{1}$, Marta Gomes da Rocha ${ }^{2}$, Luciana Pötter ${ }^{1}$, Carine Lisete Glienke ${ }^{1}$, Vagner Guasso da Costa ${ }^{1}$, Gustavo Freitas Ilha ${ }^{3}$}

\author{
1 Programa Pós-graduação em Zootecnia, Universidade Federal de Santa Maria, RS. \\ 2 Departamento de Zootecnia, Universidade Federal de Santa Maria, RS. \\ ${ }^{3}$ Curso de Medicina Veterinária - UFSM.
}

RESUMO - Avaliou-se o desempenho de bezerras de corte dos 8 aos 12 meses de idade em pastagem exclusiva de azevém (Lolium multiflorum Lam.) ou em pastagem de azevém em consórcio com trevo-vermelho (Trifolium pratense) LE 116 ou azevém com suplemento ( $1 \%$ do peso vivo (PV) por dia). O método de pastejo foi o de lotação contínua com número variável de animais. O suplemento utilizado foi ração comercial, com 17\% de proteína bruta, 23,6\% de fibra em detergente neutro e 59,6\% de nutrientes digestíveis totais. Os valores médios de massa e oferta de forragem e oferta de lâminas foliares foram de $1.327,2 \mathrm{~kg} / \mathrm{ha}$ de MS, 10,5 e 3,7 kg de MS/100 kg de PV, respectivamente. O ganho de peso médio diário foi semelhante entre as bezerras em pastagem de azevém com suplemento e aquelas em pastagem de azevém mais trevo-vermelho, com valor médio de 1.039 gramas. A carga animal e o ganho de peso vivo por área foram maiores quando animais receberam suplemento. A suplementação proporcionou efeito aditivo no consumo total de matéria seca e substitutivo no consumo de matéria seca do pasto.

Palavras-chave: escore de condição corporal, oferta de lâminas foliares, suplementação, Trifolium pratense

\section{Alternatives of utilization of Italian ryegrass pasture for rearing of beef heifers}

\begin{abstract}
The beef heifers performance from eight to twelve months of age was evaluated in exclusive Italian ryegrass (Lolium multiflorum Lam.) pasture, ryegrass plus red clover (Trifolium pratense) LE 116 or in ryegrass pasture receiving supplement in proportion of $1 \% \mathrm{BW}$. The continuous grazing method with variable stocking rate was used. The supplement used was a commercial ration, with $17 \%$ of crude protein, $23.6 \%$ of neutral detergent fiber and $59.6 \%$ of total digestible nutrients. The means values of forage mass and offer and leaf blade offer were $1327.2 \mathrm{~kg} / \mathrm{ha}$ of DM and 10.5 and $3.7 \mathrm{~kg}$ of DM/100 kg of BW, respectively. The daily body weight gain was similar for beef heifers receiving supplement or in Italian ryegrass plus red clover, with mean value of 1039 grams. The stocking rate and body gain per area were higher when animals were supplemented. The use of supplementation for grazing heifers caused additive effect on the total dry matter intake and replacement in the grass dry matter intake.
\end{abstract}

Key Words: body condition score, leaf blade on offer, supplementation, Trifolium pratense

\section{Introdução}

No Rio Grande do Sul, as fêmeas de corte com 12 a 24 meses de idade são em número aproximado de 1,4 milhões, representando $12,3 \%$ do rebanho bovino do estado. No período de 2003 a 2005, houve aumento de $7,6 \%$ no abate de fêmeas bovinas adultas. No ano de 2006, ocorreu reduçãode $35 \%$ no abate desta categoria em relação a 2005 (ANUALPEC, 2006), mostrando tendência de aumento numérico do rebanho de cria. Essa mudança exige que maior número de animais entre no sistema de produção e, conseqüentemente, estimula a redução da idade de acasalamento das fêmeas, principalmente pelo incremento de suas condições alimentares.
A nutrição adequada das fêmeas de corte é determinante para que ocorra redução da idade por ocasião do primeiro acasalamento e na taxa de natalidade. A redução na idade de acasalamento conduz a alteração na estrutura do rebanho de cria, diminuindo o intervalo de gerações e a participação de animais improdutivos na composição do rebanho. Para mudanças no nível nutricional, são utilizadas gramíneas forrageiras cultivadas de inverno, gramíneas consorciadas com leguminosas e/ou fornecimento de suplemento.

Consorciar gramíneas com leguminosas visa à complementaridade no ciclo de produção de forragem das espécies utilizadas, favorece o desenvolvimento da gramínea pelo aumento no aporte de nitrogênio $(\mathrm{N})$ no sistema solo, 
pela fixação biológica do nitrogênio pela leguminosa e possibilita ainda, maior valor nutritivo da forragem consumida, importante para animais jovens, que necessitam alto desempenho individual (Paim, 1988).

O fornecimento de suplementos para fêmeas de corte, em espécies forrageiras de clima temperado, visa aliar o desempenho individual, que deve ser pelo menos semelhante ao da pastagem exclusiva, com maior número de animais por unidade de área, atingindo o desenvolvimento previsto para o acasalamento antecipado.

A premissa básica da incorporação de animais nos protocolos de avaliação é que os dados de experimentação sejam representativos dos sistemas de produção e das situações às quais se pretende aplicá-los (Pedreira, 2001). Assim, o trabalho foi conduzido com objetivo de avaliar o desenvolvimento corporal de novilhas dos 8 aos 12 meses de idade submetidas a diferentes estratégias do uso da pastagem de azevém (Lolium multiflorum Lam.): uso exclusivo de azevém, pastagem de azevém consorciada com trevo-vermelho (Trifolium pratense) LE 116 e animais em pastejo recebendo suplemento.

\section{Material e Métodos}

O experimento foi desenvolvido em área do Departamento de Zootecnia da Universidade Federal de Santa Maria(UFSM), localizado na região fisiográfica denominada Depressão Central, com altitude de $95 \mathrm{~m}$, latitude $29^{\circ} 43^{\prime} \mathrm{Sul}$ e longitude $53^{\circ} 42^{\prime}$ Oeste. O clima da região é Cfa (subtropical úmido), conforme classificação de Köppen (Figura 1). O solo da área experimental é classificado como Argissolo Vermelho Distrófico arênico (EMBRAPA, 1999) e pertence à unidade de mapeamento São Pedro. Os dados médios da análise química do solo da área experimental são: $\mathrm{pH}$ em água - 4,8; Ca - 2,6 $\mathrm{cmol}_{\mathrm{C}} / \mathrm{dm}^{3} ; \mathrm{Mg}-2,5 \mathrm{cmol}_{\mathrm{C}} / \mathrm{dm}^{3} ; \mathrm{Al}-$ $0,9 \mathrm{cmol}_{\mathrm{C}} / \mathrm{dm}^{3}$; CTC efetiva - 7,0 $\mathrm{cmol}_{\mathrm{C}} / \mathrm{dm}^{3}$; CTC $\mathrm{pH} 7,0$ $16,8 \mathrm{cmol}_{\mathrm{C}} / \mathrm{dm}^{3}$; saturação Al - 15,4\%; saturação bases 42,6\%; índice SMP-5,3; matéria orgânica -3,0\%; P-4,7 mg/dm³ e $\mathrm{K}-57 \mathrm{mg} / \mathrm{dm}^{3}$.

A área experimental utilizada totaliza 6,0 ha, com oito subdivisões de aproximadamente 0,75 ha (unidades experimentais) mais uma área de aproximadamente 1,8 ha para a permanência dos animais reguladores.

O desempenho de bezerras de corte em recria foi avaliado em pastagem cultivada exclusiva de azevém (Lolium multiflorum Lam.); em pastagem de azevém em consórcio com trevo-vermelho (Trifolium pratense) LE 116; ou em pastagem de azevém com suplementação em quantidade correspondente a $1 \%$ do peso vivo (PV) por dia.

As bezerras receberam o suplemento diariamente, às $14 \mathrm{~h}$. Como suplemento utilizou-se ração comercial, com $17 \%$ de proteína bruta (PB), 23,6\% de fibra em detergente neutro (FDN) e 59,6\% de nutrientes digestíveis totais (NDT), composta por grão de milho moído, farelo de soja, farelo de trigo e farelo de arroz.

A pastagem foi estabelecida com três gradagens, em 9/5/2005, com semeadura a lanço, utilizando-se $40 \mathrm{~kg} / \mathrm{ha}$ de semente de azevém e $10 \mathrm{~kg} / \mathrm{ha}$ de semente de trevo-vermelho.

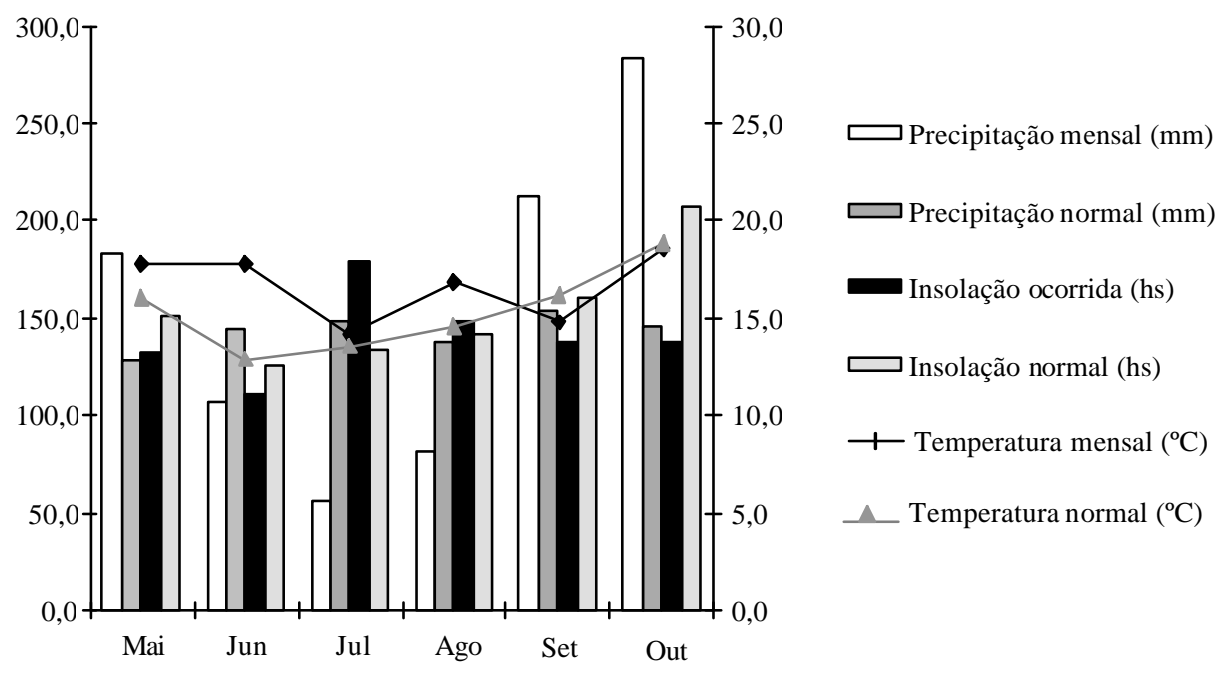

Figura 1 - Médias mensais de temperatura, precipitação pluviométrica e insolação verificadas de maio a outubro de 2005, em Santa Maria, Rio Grande do Sul, e média de 30 anos de observação. 
Por ocasião da semeadura, foram utilizados $200 \mathrm{~kg} / \mathrm{ha}$ de adubo da fórmula 05-20-20 (N-P-K) e, em cobertura, foram realizadas três aplicações de nitrogênio na forma de uréia, totalizando $67,5 \mathrm{~kg} / \mathrm{ha}$. Antecedendo a coleta dos dados experimentais (de 4/8 e 13/10/2005, totalizando 72 dias), houve um período de nove dias (25/7 a 3/8) para adaptação dos animais ao suplemento e à pastagem. Os animais tiveram livre acesso a água e sal comum.

Utilizaram-se 45 bezerras, produtos do cruzamento entre as raças Charolês e Nelore, pertencentes ao rebanho do Setor de Bovinocultura de Corte da UFSM, com média de 8 meses de idade e peso vivo inicial de $158,3 \pm 17,1 \mathrm{~kg}$.

As pesagens dos animais foram realizadas em intervalos de 21 dias, com exceção do último período, que teve duração de 28 dias. Foi respeitado jejum prévio de sólidos e líquidos de 12 horas, antecedendo as pesagens. Nestas ocasiões, os animais foram submetidos à avaliação subjetiva da condição corporal (ECC), por dois avaliadores, pela metodologia adaptada de Lowman et al. (1973), com escores variando de 1,0 (muito magro) a 5,0 (muito gordo).

O método de pastejo foi o de lotação contínua, utilizando-se três bezerras-teste por piquete, com número variável de animais reguladores. A massa de forragem (MF) foi mantida entre 1.000 e $1.500 \mathrm{~kg} / \mathrm{ha}$ de matéria seca (MS).

$\mathrm{Na}$ determinação da massa de forragem, utilizou-se a técnica de estimativa visual com dupla amostragem, realizada a cada dez dias, calculando-se a massa de forragem por equação de regressão entre as estimativas visuais e cortadas (Gardner, 1986). Para determinação da taxa de acúmulo diário de forragem (TAD, $\mathrm{kg} / \mathrm{ha}$ de MS), foram utilizadas três gaiolas de exclusão ao pastejo por repetição. As perdas de forragem (PF) foram determinadas por metodologia proposta por Hillesheim (1998) e a produção total de MS (PTMS) por piquete foi calculada pelo somatório da produção em cada período (TAD $\times \mathrm{n} \underline{\mathrm{o}}$ dias do período) com a massa de forragem no início do pastejo.

O ganho médio diário (GMD) das bezerras-teste foi obtido pela diferença dos pesos final e inicial em cada período experimental dividida pelo número de dias do período, considerando a média dos ganhos dos animais-teste como o GMD de sua unidade experimental. A carga animal (CA) por hectare, por período, expressa em $\mathrm{kg} / \mathrm{ha}$ de $\mathrm{PV}$, foi calculada pelo somatório do peso médio das bezerras-teste com o peso médio de cada bezerra reguladora multiplicado pelo número de dias que permaneceram na repetição dividido pelo número de dias do período experimental. A produção de peso vivo por hectare (GPV/ha) por período foi obtida pelo produto da taxa de lotação, do ganho médio diário e do número de dias do período. O ganho de peso vivo total em cada sistema de alimentação foi obtido pela soma dos ganhos de peso em cada período.

A estimativa da composição bromatológica do pasto foi determinada em amostras coletadas por simulação de pastejo (Euclides et al., 1992). As amostras colhidas foram levadas a estufa com circulação forçada de ar a $55^{\circ} \mathrm{C}$, por 72 horas e depois foram trituradas em moinho tipo Willey e analisadas quanto à composição em proteína bruta $(\mathrm{PB}) \mathrm{e}$ fibra em detergente neutro (FDN) utilizando-se a metodologia da AOAC (1995) e a digestibilidade in vitro da matéria orgânica (DIVMO), de acordo com Tilley \& Terry (1963). O teor de nutrientes digestíveis totais (NDT) foi estimado pela equação: NDT $=$ MO*DIVMO/100, em que MO é o percentual de matéria orgânica (Barber et al., 1984).

A oferta de forragem (OF) foi calculada pela equação: ((MF/nodias) + TAD)/CA do período e expressa em kg MS/ $100 \mathrm{~kg}$ PV. A oferta de lâminas foliares verdes (OLFV) foi calculada pela equação: (((MF *\% folhas $) / n^{\circ}$ dias $)+$ TAD * $\%$ folha)/CA, expressa em $\mathrm{kg} \mathrm{MS} / 100 \mathrm{~kg} \mathrm{PV}$.

O desaparecimento diário de forragem foi estimado da seguinte forma: produção total de MS de forragem menos MF no final do período experimental menos perdas de forragem durante o período de pastejo, dividido pelo número de dias do período. $\mathrm{O}$ desaparecimento diário de forragem, dividido pela carga animal e multiplicado por 100, foi considerado consumo diário de forragem, expresso em \% PV.

As taxas de substituição e adição do consumo de MS do suplemento sobre o consumo de MS de forragem foram estimadas a partir do cálculo proposto por Hodgson (1990), em que: substituição = $($ (consumo de MS de forragem dos animais sem suplementação menos consumo de MS dos animais sob suplementação), dividido consumo de MS do suplemento*100); adição = ((consumo total de MS dos animais sob suplementação menos consumo de MS da forragem dos animais sem suplementação), dividido pelo consumo de MS do suplemento*100).

O delineamento experimental foi o inteiramente casualizado, com parcelas subdivididas no tempo com número variado de repetições. A pastagem exclusiva de azevém teve duas repetições de área e as demais, três. Os resultados foram submetidos à análise de variância e ao teste Tukey de comparação de médias, com nível de 5\% de significância, utilizando-se o programa estatístico SAS versão 6.08 (1990). Quando não foi detectada diferença entre as pastagens, foi realizado teste de contraste entre a pastagem de azevém exclusiva e aquela com leguminosa. $\mathrm{O}$ modelo matemático geral referente à análise das variáveis estudadas foi representado por: $Y_{i j k}=\mu+T_{i}+P_{j}+R_{k}\left(T_{i}\right)$ $+(\mathrm{TP})_{\mathrm{ij}}+\varepsilon_{\mathrm{ijk}}$, em que: $\mathrm{Y}_{\mathrm{ijk}}=$ variáveis dependentes; $\mu=$ 
média de todas as observações; $\mathrm{T}_{\mathrm{i}}=$ efeito do $\mathrm{i}$-ésimo tratamento; $\mathrm{R}_{\mathrm{k}}\left(\mathrm{T}_{\mathrm{i}}\right)=$ efeito da k-ésima repetição dentro do i-ésimo tratamento (erro a); $\mathrm{P}_{\mathrm{j}}=$ efeito do j-ésimo período; $(\mathrm{TP})_{\mathrm{ij}}=$ interação i-ésimo tratamento $\times$ j-ésimo período; e $\varepsilon_{\mathrm{ijk}}=$ erro experimental residual (erro b).

Os dados da composição botânica da pastagem para as alternativas de utilização de azevém para os períodos avaliados foram submetidos à análise de ordenação (análise de coordenadas principais) pelo pacote estatístico MULTIV (Pillar, 1997).

\section{Resultados e Discussão}

Não houve interação $(\mathrm{P}>0,05)$ formas de utilização de azevém $\times$ períodos para massa de forragem $(\mathrm{MF})$, oferta de forragem (OF) e oferta de lâminas foliares verdes (OLFV). Não houve diferença $(\mathrm{P}>0,05)$ entre as pastagens de azévem para estas variáveis, o que reflete o manejo correto na adequação da carga animal nas alternativas de utilização da pastagem de azevém. Os animais foram submetidos a massas de forragem de $1.327,2 \mathrm{~kg} / \mathrm{ha}$ de MS, ofertas de forragem de $10,5 \mathrm{~kg}$ de MS/100 de PV e ofertas de lâminas foliares verdes de $3,7 \mathrm{~kg}$ de MS/100 kg de PV. A produção de matéria seca total não diferiu $(\mathrm{P}>0,05)$ entre as alternativas de utilização, com valor médio de $4.680 \mathrm{~kg} / \mathrm{ha}$ de MS. Na mesma área experimental, Macari (2006) observou produção de MS de $3.006,2 \mathrm{~kg} / \mathrm{ha}$ para azevém em consórcio com aveia (Avena strigosa), representando $51,83 \%$ da produção total da mis tura. A taxa média de acúmulo de forragem, $44,5 \mathrm{~kg} / \mathrm{ha}$ de MS, está dentro dos valores médios relatados na bibliografia para gramíneas de clima temperado. A fertilidade do solo foi caracterizada por valores muito baixos de fósforo e potássio, enquanto a matéria orgânica apresentou teor médio. A precipitação pluviométrica correspondeu a 113,5\% da média dos últimos 30 anos (Figura 1).

A composição botânica e estrutural da pastagem não foi influenciada $(\mathrm{P}>0,05)$ pela associação formas de utilização azevém $\times$ períodos. As formas de utilização do azevém não ocasionaram diferença $(\mathrm{P}>0,05)$ nos componentes estruturais, provavelmente em razão do encerramento da tomada de dados da pastagem em 14/10, com o azevém em florescimento, para assegurar a ressemeadura natural dessa espécie na área. O agrupamento dos componentes botânicos e estruturais da pastagem (Figura 2) foi

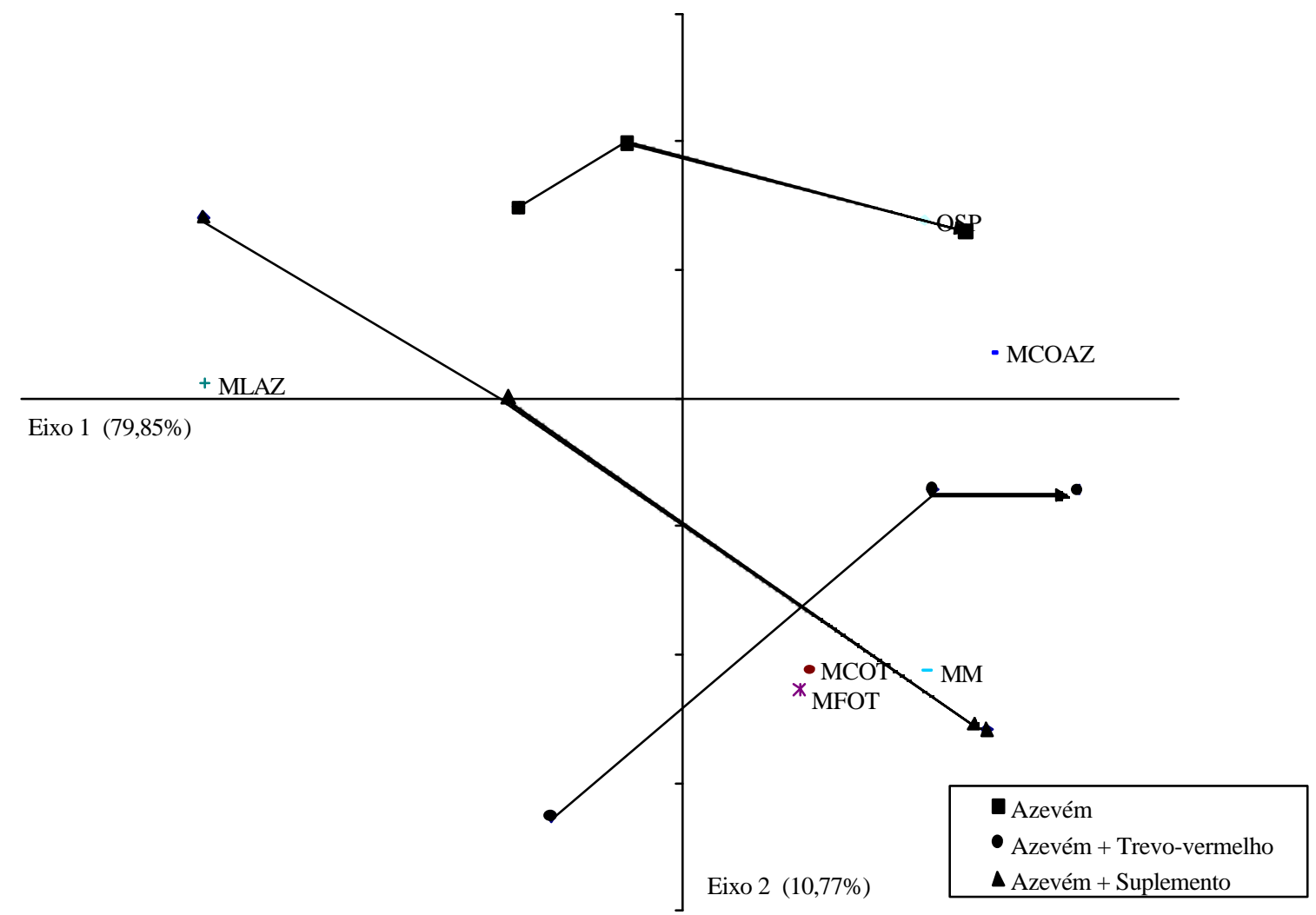

Figura 2 - Ordenação dos componentes botânicos e estruturais: massa de lâmina de azevém (MLAZ), massa de colmode azevém (MCOAZ), massa de folha de trevo-vermelho(MFOT), massa de colmo de trevo (MCOT), material morto (MM) e outras espécies (OSP), em kg/ha de MS, em pastagem de azevém exclusivo, pastagem de azevém consorciado com trevo-vermelho e azevémmais $1 \%$ do peso vivo de suplemento. $(1=9 / 8-27 / 8 / 2005 ; 2=28 / 8-16 / 9 / 2005 ; 3=17 / 9-14 / 10 / 2005)$. Valores decorrelaçãodas variáveis com o eixo 1: $\mathrm{MLAZ}=-0,948 ; \mathrm{MCAZ}=0,131 ; \mathrm{MFOT}=0,276 ; \mathrm{MCOT}=0,883 ; \mathrm{MM}=0,023 ; \mathrm{OSP}=0,817 ;$ e com o eixo 2: MLAZ $=0,305 ;$ MCAZ $=-0,634$, MFOT $=0,376 ;$ MCOT $=0,927 ; \mathrm{MM}=-0,775 ;$ OSP $=0,562$. 
resultado da correlação entre a contribuição desses componentes com os eixos 1 e 2 . O eixo 1 sintetizou $79,85 \%$ da variação dos componentes da pastagem, enquanto o eixo 2 sintetizou $10,77 \%$ desta variação.

A variação dos componentes estruturais ocorreu principalmente em decorrência do ciclo das forrageiras, caracterizado pela maior presença de lâminas foliares de azevém no início do ciclo e predominância de colmos e material morto no final. A participação de colmos e folhas de trevovermelho só foi representativa a partir do final do mês de agosto, que correspondeu ao final do primeiro período de avaliação. A participação de inflorescências de azevém e de trevo-vermelho não foi considerável e, por isso, não foi contabilizada. Na pastagem de azevém utilizada com suplemento, houve maior quantidade de massa de lâminas de azevém no início e metade do ciclo da pastagem, o que pode ser explicado pelo manejo realizado anteriormente, de adaptação dos animais ao suplemento, e pela menor seletividade de folhas de azevém no período de adaptação, que pode ser indicativo de menor dependência do pasto na dieta dos animais sob suplementação. Maior presença de lâminas foliares na pastagem utilizada com suplemento também foi observada por Rocha et al. (2004), no entanto, esse resultado difere do observado por Frizzo et al. (2003a), de menor participação de lâmina de azevém quando os bovinos receberam níveis elevados de suplemento durante todo o ciclo da pastagem, caracterizando maior seletividade para esse componente. Esses resultados divergentes indicam que a desfolhação é alterada quando os animais recebem suplemento, criando oportunidades para que a estrutura da pastagem se modifique. O maior acúmulo de material morto na pastagem utilizada com suplemento provavelmente foi decorrente da senescência das lâminas foliares não consumidas. A menor cobertura do solo pelo azevém no início de seu estádio reprodutivo, com redução na participação de lâminas foliares, propiciou espaço para o desenvolvimento de espécies oportunistas e "outras espécies" apresentaram maior predomínio na pastagem exclusiva de azevém. Essa participação ocorreu com menor intensidade na pastagem de azevém utilizada com suplemento, como conseqüência do acúmulo de material morto no final do ciclo, e, na pastagem de azevém + trevo-vermelho, em razão do hábito de crescimento ereto a decumbente dessa leguminosa, com maior cobertura do solo.

Não houve interação $(\mathrm{P}>0,05)$ forma de utilização do azevém $\times$ períodos para ganho de peso médio diário (GMD) e para escore de condição corporal (ECC), no entanto, o ganho médio diário diferiu $(\mathrm{P}<0,05)$ entre as alternativas de utilização do azevém, com suplemento ou com leguminosa (Tabela 1).

O ganho médio diário das bezerras na pastagem utilizada com suplemento diferiu significativamente em relação ao daquelas mantidas na pastagem de azevém exclusivo, mas não diferiu $(\mathrm{P}>0,05)$ do observado nos animais em pastagem de azevém + trevo-vermelho. A composição bromatológica da forragem consumida não explica as diferenças de ganho, pois, independentemente das alternativas de utilização dapastagem, as bezerras colheram forragem com teores semelhantes ( $\mathrm{P}>0,05)$ de PB $(24,8 \%)$, FDN $(36,4 \%)$ e NDT $(74,9 \%)$. Esses parâmetros variaram no decorrer do ciclo da pastagem $(\mathrm{P}<0,05)$. O manejo imposto para assegurar que as massas de forragem não diferissem entre as formas de utilização do azevém resultou em oferta de forragem de $10,5 \mathrm{~kg}$ MS/100 kg PV e oferta de lâminas foliares de $3,7 \mathrm{~kg} \mathrm{MS} / 100 \mathrm{~kg} \mathrm{PV}$, o que permitiu aos animais exercerem seletividade similar e, provavelmente, não limitou o consumo de pasto. A explicação para as diferenças nos ganhos individuais poderia ser, então, a diferença na quantidade de matéria seca consumida pelos animais.Somente os dados referentes à estimativa de consumo de matéria seca na pastagem de azevém exclusiva e na pastagem de azevém utilizada com suplemento foram utilizados, uma vez os valores que dão origem ao cálculo do consumo na pastagem de azevém + trevo-vermelho foram inconsistentes.

As bezerras apresentaram consumo médio de forragem de $3,58 \%$ do PV, valor $37 \%$ superior ao descrito pelo NRC (1996) para animais desta categoria, e ganho de $0,993 \mathrm{~kg} / \mathrm{dia}$ (Tabela 2).

Tabela 1 - Ganho médio diário e condição corporal de bezerras de corte em pastagem de azevém exclusiva consorciada com trevo-vermelho ou associada a suplemento

\begin{tabular}{lccc}
\hline & $\begin{array}{c}\text { Ganho médio diário } \\
(\mathrm{kg} / \text { animal })\end{array}$ & $\begin{array}{c}\text { Condição corporal em 14/10 } \\
\text { (pontos, 1-5) }\end{array}$ & $\begin{array}{c}\text { Ganho em escore de condição corporal } \\
(\text { pontos, 1-5) }\end{array}$ \\
\hline Azevém + suplemento & $1,153 \mathrm{a}$ & 3,12 & 0,38 \\
Azevém + trevo-vermelho & $0,925 \mathrm{ab}$ & 3,03 & 0,30 \\
Azevém exclusiva & $0,857 \mathrm{~b}$ & 3,00 & 0,26 \\
CV $(\%)$ & 13,98 & 1,81 & 29,64 \\
\hline
\end{tabular}

a, b na mesma coluna diferem $(\mathrm{P}<0,05)$.

GMD $=1,48-0,0291 \mathrm{x}+0,000337 \mathrm{x}^{2} ; \mathrm{R}^{2}=26,21 \% ; \mathrm{P}=0,022 ; \mathrm{x}=$ dias de pastejo.

$\mathrm{ECC}=2,73+0,004 \mathrm{x} ; \mathrm{R}^{2}=83,57 \% ; \mathrm{P}=0,0001 ; \mathrm{x}=$ dias de pastejo. 
Tabela 2 - Estimativas de consumo de matéria seca(MS) do pasto, taxa de substituição do consumo de MS do pasto por suplemento e taxa de adição no consumo total de MS obtidas com bezerras de corte em pastagem de azevém exclusiva ou com suplemento

\begin{tabular}{lccc}
\hline Tratamento & $\begin{array}{c}\text { Consumo MS pasto } \\
(\% \mathrm{PV})\end{array}$ & $\begin{array}{c}\text { Taxa de substituição } \\
(\mathrm{kg} \text { MS pasto/kg MS suplemento) }\end{array}$ & $\begin{array}{c}\text { Taxa de adição } \\
(\%)\end{array}$ \\
\hline Azevém exclusiva & 3,6 & - & - \\
Azevém + suplemento & 3,5 & 0,16 & 83,3 \\
\hline
\end{tabular}

O melhor desempenho dos animais na pastagem utilizada com suplemento, em comparação ao daqueles na pastagem exclusiva de azevém, pode ser explicado pelo maior consumo total de matéria seca, resultado da taxa de adição do consumo do suplemento ao consumo de matéria seca do pasto (Tabela 2). O efeito aditivo do suplemento sobre o consumo total de MS foi de $83,3 \%$, enquanto Freitas et al. (2005) observaram efeito aditivo de 78,2\% para o nível de $0,9 \%$ de farelo de trigo para animais de mesma categoria. A suplementação aos animais em pastejo permitiu aumento de $34,5 \%$ no ganho médio diário em relação aos animais mantidos em pastagem exclusiva de azevém e de $24,6 \%$ em relação ao dos animais mantidos na pastagem de azevém + trevo-vermelho. Esses resultados divergem da afirmação de Rearte \& Pieroni (2001) de que, em pastagens temperadas, espera-se que o efeito do suplemento seja mais substitutivo que aditivo. O valor da taxa de substituição do consumo de pasto pelo consumo de suplemento (Tabela 2) pode ser considerado pequeno e há correlação negativa entre taxa de substituição e desempenho individual (Bargo et al., 2003). Animais que receberam suplemento ingeriram maior quantidade de matéria seca e, conseqüentemente, o aporte energético foi maior. Provavelmente, com o uso de suplemento, não houve redução na digestibilidade da fibra do pasto e no seu consumo nem aumento da taxa de substituição da MS do pasto pela MS do suplemento.

Para o ganho de peso médio observado, o teor de proteína bruta (PB) no pasto consumido, 24,8\%, esteve sempre acima dos $13,7 \%$ exigidos para essa categoria animal (NRC, 1996). Quando a PB excede as exigências para o animal, pode causar desbalanço nutricional, pois parte do nitrogênio é utilizada como fonte de energia e parte é excretada. Nesta situação, existe um custo energético en volvido, que reduz a eficiência de utilização da energia e pode diminuir o desempenho animal (Van Soest, 1994). O suplemento oferecido também apresentou teor de PB superior às exigências da categoria, com 1,16 kg de NDT adicional/bezerra por dia. A relação NDT:PB foi semelhante em pasto e suplemento, com valor médio de 3,3; então, certamente houve excesso de nitrogênio, o que não ocorre quando a relação é superior a 7 (Moore et al., 1999). O acréscimo na absorção do nitrogênio no intestino delgado, decorrente da menor degradabilidade ruminal da proteína do suplemento, também pode ser fator que explique o melhor desempenho dos animais que receberam suplemento. $\mathrm{O}$ valor de energia metabolizavel fornecido pelo pasto, $2,74 \mathrm{Mcal} / \mathrm{kg}$ de MS, foi semelhante ao exigido pelos animais, 2,66 Mcal/kg de MS. Assim, a contribuição do suplemento para o maior ganho médio diário foi devido ao aumento no consumo total de matéria seca, pois houve melhor balanceamento na relação $\mathrm{C}: \mathrm{N}$ dos nutrientes consumidos. Por outro lado, quando o valor de PB do suplemento é inferior ao valor das exigências da categoria em pastejo, pode existir desbalanceamento na dieta dos animais, e animais suplementados apresentarem GMD semelhante aos exclusivamente em pastagem, como verificado quando bezerras de corte receberam $1 \%$ de sorgo moído $(6,1 \%$ PB e 53,9\% NDT) como suplemento em pastagem de azevém e aveia (Rocha et al., 2003).

O ganho médio diário semelhante entre as pastagens na ausência dos dados de consumo de MS pode, em parte, ser explicado pela participação percentual de 5,3 da MS do trevo-vermelho na massa de forragem. Ganhos de até $1.016 \mathrm{~kg} /$ dia em novilhos de corte foram observados em pastagem consorciada de azevém, trevo-branco (T. repens) e cornichão (L. corniculatus), com 2,89\% de participação da MS das leguminosas (Marchezan et al., 2002). O maior ganho de peso observado quando animais alimentam-se de leguminosas é conseqüência de fatores que incluem a maior taxa de quebra de partículas e digestão ruminal, a maior quantidade de nitrogênio não-amoniacal atingindo o intestino delgado e a maior eficiência da utilização da energia (Laidlaw \& Teuber, 2001). Essa afirmação foi parcialmente verificada, pois o ganho médio diário dos animais na pastagem de azevém + trevo-vermelho foi 7,9\% superior em relação ao daqueles mantidos na pastagem exclusiva de azevém e não diferiu do ganho observado nos animais que recebiam suplemento. Em estudo realizado por Rocha et al. (2003), a participação de 3,4\% de MS do trevo-vesiculoso (T. vesiculosum) na MS total da pastagem de aveia (A. strigosa) e azevém não determinou diferença no ganho médio diário dos animais em comparação aos animais sob suplementação ou em pastagem de aveia e azevém adubada com $300 \mathrm{~kg} / \mathrm{ha}$ de nitrogênio. 
Até o início do pastejo, provavelmente os animais não tiveram condições para expressar seu potencial de crescimento, pois seu peso era de $158,3 \mathrm{~kg}$ aos 8 meses de idade. O ganho médio diário $(0,993 \mathrm{~kg})$ pode ser atribuído, em parte, a essa limitação anterior de nutrientes que podem provocar o crescimento compensatório.Conforme descrito por Ryan (1990), a magnitude do crescimento animal, expressa no aumento do tamanho e peso, é determinada pelas limitações do ambiente.

Animais em diferentes alternativas de utilização da pastagem de azevém tiveram escores de condição corporal semelhantes $(\mathrm{P}>0,05)$, provavelmente em decorrência da maior aquisição de tecido muscular, previsível principalmente em animais jovens que passaram por restrição alimentar. O escore de condição corporal apresentou aumento linear significativo $(\mathrm{P}<0,05)$ conforme aumentou o período de utilização da pastagem, com ganho de 0,004 pontos a cada dia de pastejo.Assim, para acréscimo de um ponto no escore de condição corporal, seria necessário aumento de $233 \mathrm{~kg}$ de PV e, pelo estudo de contrastes, animais recebendo suplemento apresentaram, ao final da estação de pastejo, escore de condição corporal maior $(\mathrm{P}<0,05)$ que o daqueles mantidos exclusivamente em pastagem. Por seu menor aporte energético, os animais que não receberam suplemento necessitariam $28,6 \mathrm{~kg}$ a mais de aumento de peso para atingirem o mesmo escore de condição corporal dos animais em pastagem com suplemento, o que corresponderia, conservando o mesmo valor numérico de ganho de peso, a 32 dias a mais de pastejo. As bezerras em pastagem exclusiva de azevém e em pastagem de azevém com suplemento apresentaram escores de condição corporal de 3,02 e 3,12 pontos, respectivamente, superiores ao valor mínimo recomendado $(3,0)$ para novilhas em estação de acasalamento (Rocha, 1997).O ganho no escore de condição corporal não diferiu $(\mathrm{P}>0,05)$ entre as alternativas de utilização do azevém e variou de 0,26 a 0,38 pontos.

Não houve interação $(\mathrm{P}>0,05)$ alternativa de utilização do azevém $\times$ períodos para carga animal e ganho de peso vivo por área nem diferença $(\mathrm{P}>0,05)$ entre as alternativas de utilização da pastagem (Tabela 3 ). O estudo de contrastes indicou carga média superior $(\mathrm{P}<0,05)$ na pastagem utilizada com suplemento. No decorrer do ciclo do pasto, a conversão alimentar mostrou melhor ajuste para o modelo de regressão quadrática, apresentando menor valor no 430 o dia de pastejo, em razão da precipitação superior à normal ocorrida nesta ocasião (Figura 1).

O uso de suplemento proporciou incremento de $16,8 \%$ na conversão alimentar, correspondente a $143,3 \mathrm{~kg} / \mathrm{ha}$ de $\mathrm{PV}$, como resultado do efeito substitutivo do consumo de pasto pelo consumo de suplemento. A cada $\mathrm{kg}$ de suplemento fornecido aos animais, houve redução de $0,167 \mathrm{~kg}$ de MS do pasto consumido (Tabela 2). Quando os animais receberam suplemento, o ganho de peso por área foi superior $(\mathrm{P}<0,05)$ ao daqueles mantidos em pastagem exclusiva de azevém. O uso do suplemento proporcionou aumento de $45,56 \%$ no ganho de peso por área, decorrente do aumento no ganho médio diário e na taxa de lotação. O mesmoefeito substitutivo/aditivo do uso de suplemento também foi verificado por Frizzo et al. (2003b) em pastagens de clima temperado quando houve restrição no consumo de pasto aos animais em pastejo.

Macari (2006) observou ganhos de peso vivo por área crescentes de 442,1 até $684,4 \mathrm{~kg}$, conforme o nível de suplemento utilizado ( 0 a $0,9 \%)$. Os valores observados por este autor podem ser atribuídos ao maior período de utilização da pastagem e à maior carga animal. Também Rocha et al. (2003) observaram GPA de 602,8 kg e 509,8 kg para animais em pastagem hibernal com e sem suplemento. Estas diferenças confirmam a capacidade biológica do uso de suplementos de aumentar significativamente a produção animal por unidade de área.

Houve interação $(\mathrm{P}<0,05)$ alternativas de utilização do azevém $\times$ períodos para o peso vivo. A evolução do peso vivo no período experimental se ajustou ao modelo linear para todas as formas de utilização do azevém (Figura 3). As bezerras avaliadas neste trabalho, considerando peso adulto de $450 \mathrm{~kg}$, apresentaram 49,6; 49,4 e 53,1\%, respectivamente, desse peso nas pastagens de azevém exclusiva, de azevém + trevo-vermelho e de azevém + suplemento, respectivamente, ao final do período de pastejo. O ganho adicional das bezerras sob suplementação correspondeu a $0,262 \mathrm{~kg}$ de peso vivo por diade utilização da pastagem em

Tabela 3 - Carga animal, número de animais por hectare e ganho de peso vivo por área em pastagens de azevém, azevém + trevo-vermelho ou azevém + suplemento

\begin{tabular}{lccc}
\hline & Carga animal $(\mathrm{kg} / \mathrm{ha}$ de $\mathrm{PV})$ & Animais por hectare & Ganho de peso vivo por área (kg/ha) \\
\hline Azevém + trevo-vermelho & $853,3 \mathrm{~b}$ & 4,5 & $298,3 \mathrm{~b}$ \\
Azevém + suplemento & $996,6 \mathrm{a}$ & 5,0 & $434,2 \mathrm{a}$ \\
\hline
\end{tabular}

a, b na mesma coluna, diferem entre si $(\mathrm{P}<0,05)$.

Carga animal $=1366,35-28,46 x+0,33 x^{2} ; R^{2}=38,1 ; P=0,005 ; x=$ dias de pastejo. 


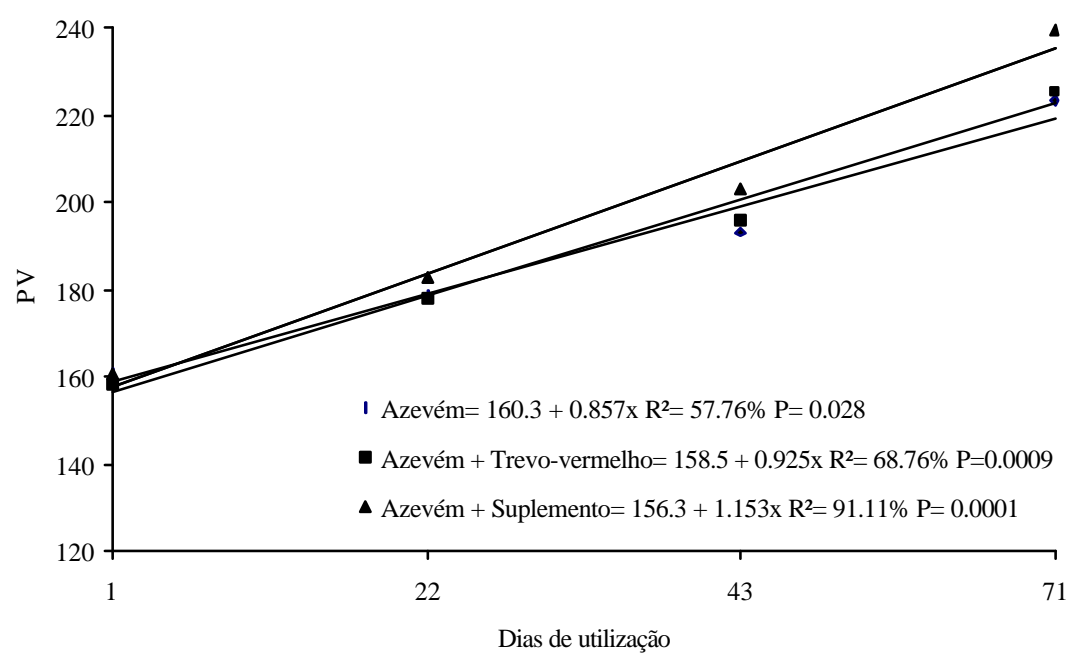

Figura 3 - Evolução do peso corporal (kg) de bezerras de corte mantidas em pastagem de azevém ( $\bullet$ ), azevém + trevo-vermelho ( e azevém + suplemento $(\boldsymbol{\Delta})$.

relação ao dos animais que não receberam suplemento. Considerando peso adulto de $450 \mathrm{~kg}$ para essas fêmeas, o peso-alvo para manifestação da puberdade seria atingido 34 dias antes, quando receberam suplemento. A permanência dos animais com ganhos semelhantes aos realizados nos respectivas alternativas de utilização do azevém por período maior de tempo, considerando a diferença no ganho, permitiria às fêmeas que receberam suplemento atingirem $65 \%$ do peso adulto no dia 27 de novembro, enquanto aquelas que não receberam suplemento atingiriam esse percentual em 31 de dezembro. Para atingir bons índices de prenhez ao primeiro acasalamento, no entanto, o peso-alvo para manifestar a puberdade deveria ser atingido em 15/11, ao início do período de acasalamento (Rocha \& Lobato, 2002), o que inviabilizaria o acasalamento aos 14-15 meses de idade das fêmeas que receberam suplemento. Frizzo et al. (2003b) trabalharam com fêmeas do mesmo rebanho, em média $34 \mathrm{~kg}$ mais pesadas, no início de utilização da pastagem hibernal e observaram percentual de estro de $69,65 \%$ entre as fêmeas que receberam suplemento e de $9 \%$ naquelas exclusivamente em pastagem, o que viabilizou o acasalamento desses animais aos 14-15 meses de idade. Assim, para redução da idade de acasalamento, mais que o ganho proporcionado pela pastagem de inverno, devem ser considerados o peso dos animais no início do período de pastejo e o número de dias de utilização da pastagem.

Neste experimento, o peso médio das bezerras aos 8 meses de idade foi de $35,18 \%$ do peso adulto. Rocha \& Lobato (2002) recomendam no mínimo $40 \%$ do peso adulto nesta idade para acasalamento 14-15 meses de idade. Quando o objetivo é obter o primeiro acasalamento aos 18 mesesde idade, o ganho médio diário necessário para atingir o percentual de $65 \%$ do peso adulto dos 12 aos 18 meses de idade seria de 0,297 kg e 0,392 kg, respectivamente, para animais que recebem suplemento e para aqueles sem suplementação.

\section{Conclusões}

Em pastagem de azevém (Lolium multiflorum Lam.) utilizada por bezerras de corte, a combinação do aumento na taxa de lotação e do ganho de peso médio diário provocados pelo fornecimento de suplemento aos animais em pastejo possibilita maior ganho de peso vivo e maior número de animais por unidade de área. Os efeitos do fornecimento de suplemento para as bezerras em pastagem de azevém são de substituição do consumo de pasto pelo consumo de suplemento e de adição no consumo total de matéria seca.

\section{Literatura Citada}

ANUALPEC. Anuário da Pecuária Brasileira. São Paulo: FNP. Consultoria \& Agroinfomativos. 13.ed. 2006. 369p.

ASSOCIATION OF OFFICIAL ANALYTICAL CHEMISTS - AOAC. Official methods of analysis. 14.ed. Washington: 1995. 1141p.

BARBER, W.P.B.; ADAMSON, A.H.; ALTMAN, J.F.B. New methods of feed evaluation. In: HARESIGN, W.; COLE, D.J.A. (Eds.) Recent advances in animal nutrition. London: Butterworths, 1984. p.161-176.

BARGO, F.; MULLER, L.D.; KOLVER, E.S. et al. Invited review: production and digestion of supplemented dairy cows on pasture. Journal of Dairy Science, v.86, n.4, p.1-42, 2003.

EMPRESA BRASILEIRA DE PESQUISA E AGROPECUÁRIA EMBRAPA. Centro Nacional de Pesquisa de Solos. Sistema brasileiro de classificação de solos. Brasília: Embrapa; Rio de Janeiro, 1999. 412p. 
EUCLIDES, V.P.B.; MACEDO, M.C.; OLIVEIRA, M.P. Avaliação de diferentes métodos de amostragem para estimar o valor nutritivo de forragens sob pastejo. Revista Brasileira de Zootecnia, v.21, n.4, p.691-701, 1992.

FREITAS, F.K.; ROCHA, M.G.; RESTLE, J. et al. Suplementação energética na recria de fêmeas de corte em pastagem cultivada de inverno. Produção animal. Revista Brasileira de Zootecnia, v.34, n.4, p.1256-1266, 2005.

FRIZZO, A.; ROCHA, M.G.; RESTLE, J. et al. Produção de forragem e retorno econômico da pastagem de aveia e azevém sob pastejo com bezerras de corte submetidas a níveis de suplementação energética. Revista Brasileira de Zootecnia, v.32, n.3, p.632-642, 2003a.

FRIZZO, A.; ROCHA, M.G.; RESTLE, J. et al. Suplementação energética na recria de bezerras de corte mantidas em pastagem de inverno. Revista Brasileira de Zootecnia, v.32, n.3, p.643-652, 2003b.

GARDNER, A.L. Técnicas de pesquisa em pastagens e aplicabilidade de resultados em sistemas de produção. Brasília: IICA/EMBRAPA-CNPGL. 1986. 197p. (Série publicações miscelâneas, 634).

HILLESHEIM, A. Manejo do gênero Pennisetum sob pastejo. In: SIMPÓSIO SOBRE MANEJO DA PASTAGEM, 9., 1998, Piracicaba. Anais... Piracicaba: Fundação de Estudos Agrários Luiz de Queiroz, 1998. p.77-108.

HODGSON, J. Grazing management. Science into practice. London: Longman Scientific \& Technical, 1990. 203p.

LAIDLAW, A.S.; TEUBER, N. Temperate forage grass-legume mixtures: advances and perspectives. In: INTERNATIONAL GRASSLAND CONGRESS, 19., 2001., São Paulo. Proceedings... São Paulo: Brazilian Society of Animal Husbandry, 2001. p.85-92.

LOWMAN, B.G.; SCOTT, M.; SOMERVILLE, S. Condition scoring beef cattle. Edinburgh: East of Scotland College of Agriculture, 1973. 8p. (Bulletin, 6)

MACARI, S. Recria de fêmeas de corte para acasalamento aos 18 meses de idade. 2006. 97f. Dissertação(Mestrado em Zootecnia) - Universidade Federal de Santa Maria, Santa Maria, 2006.

MARCHEZAN, E.; VIZZOTTO, V.R.; ROCHA, M.G. et al. Produção animal em várzea sistematizada cultivada com forrageiras de estação fria submetidas a diferentes níveis de adubação. Ciência Rural, v.32, n.2, p.303-308, 2002.
MOORE, J.E.; BRANT, M.H.; KUNKLE, W.E. et al. Effects of supplementation on voluntary forage intake, diet digestibility, and animal performance. Journal of Animal Science, v.77, n.S2, p.122-135, 1999.

NATIONAL RESEARCH COUNCIL - NRC. Nutrient requirements of beef cattle. 7.ed. Washington D.C.: 1996. 90p.

PAIM, N.R. Manejo de leguminosa de clima temperado. In SIMPÓSIO SOBRE MANEJO DE PASTAGEM, 9., 1988, Piracicaba. Anais... Piracicaba: Fundação de Estudos Agrários Luiz de Queiroz, 1988. p.341-358.

PEDREIRA, G.S.P.; MELLO, A.C.L.; OTANI, L. O processo de produção em pastagens. In: REUNIÃO ANUAL DA SOCIEDADE BRASILEIRA DE ZOOTECNIA, 38., 2001, Piracicaba. Anais.. Piracicaba: Sociedade Brasileira de Zootecnia, 2001. p.772-807.

PILLAR, V.D.P. Multivariate exploratory analysis and randomization testing with MULTIV. Coenoses, v.12, p.145-148, 1997.

REARTE, D.H.; PIERONI, G.A. Supplementation of temperate pastures. In: INTERNATIONAL GRASSLAND CONGRESS, 19., 2001, São Pedro. Proceedings... São Pedro: 2001. p.679-689.

ROCHA, M.G. Desenvolvimento e características de produção e reprodução de novilhas de corte primíparas aos dois anos de idade. 1997. 247f. Tese (Doutorado em Zootecnia) - Universidade Federal do Rio Grande do Sul, Porto Alegre, 1997.

ROCHA, M.G.; RESTLE, J.; FRIZZO, A. et al. Alternativas de utilização da pastagem hibernal para recria de bezerras de corte. Revista Brasileira de Zootecnia, v.32, n.2, p.383-392, 2003.

ROCHA, M.G.; RESTLE, J.; FRIZZO, A. et al. Parâmetros produtivos de uma pastagem temperada submetida a alternativas de utilização. Revista Brasileira de Zootecnia, v.33, n.6, p.1386-1395, 2004.

ROCHA, M.G.; LOBATO, J.F.P. Sistemas de alimentação pósdesmama de bezerras de corte para acasalamento $14 / 15$ meses de idade. Revista Brasileira de Zootecnia, v.31, n.4, p.1814$1822,2002$.

RYAN, W.J. Compensatory growth in cattle and sheep. Nutrition Abstracts and Reviews, v.50, p.653-664, 1990.

STATISTICAL ANALYSIS SYSTEM - SAS. SAS/STAT user's guide. 4.ed. Version 6.08. Cary: 1990. 943p.

Van SOEST, P.J. Nutritional ecology of the ruminant. 2.ed. Ithaca: Cornell University Press, 1994. 476p. 